\title{
Evaluating the impact of new anticoagulants in the hospital setting
}

\author{
Nady BRAIDY, Khai BUI, Beata BAJOREK. \\ Received (first version): 13-Aug-2010 Accepted: 12-Jan-2011
}

\begin{abstract}
${ }^{*}$
The short-comings of current anticoagulants have led to the development of newer, albeit more expensive, oral alternatives.

Objective: To explore the potential impact the new anticoagulants dabigatran and rivaroxaban in the local hospital setting, in terms of utilisation and subsequent costing.

Method: A preliminary costing analysis was performed based on a prospective 2-week clinical audit (29th June - 13th July 2009). Data regarding current anticoagulation management were extracted from the medical files of patients admitted to Ryde Hospital. To model potential costing implications of using the newer agents, the reported incidence of VTE/stroke and bleeding events were obtained from key clinical trials.

Results: Data were collected for 67 patients treated with either warfarin $(n=46)$ or enoxaparin $(n=21)$ for prophylaxis of VTE/stroke. At least two-thirds of all patients were deemed suitable candidates for the use of newer oral anticoagulants (by current therapy: warfarin: $65.2 \%$ (AF), $34.8 \%$ (VTE); enoxaparin: $100 \%$, (VTE)). The use of dabigatran in VTE/stroke prevention was found to be more costeffective than warfarin and enoxaparin due to significantly lower costs of therapeutic monitoring and reduced administration costs. Rivaroxaban was more cost-effective than warfarin and enoxaparin for VTE/stroke prevention when supplier-rebates (33\%) were factored into costing.

Conclusion: This study highlights the potential costeffectiveness of newer anticoagulants, dabigatran and rivaroxaban, compared to warfarin and enoxaparin. These agents may offer economic advantages, as well as clinical benefits, in the hospital-based management of anticoagulated patients.
\end{abstract}

Keywords: Anticoagulants. Costs and Cost Analysis. Australia.

\footnotetext{
'Beata BAJOREK. BPharm DipHospPharm PhD GradCertEdStud(HigherEd). Faculty of Pharmacy, University of Sydney, and Northern Sydney Central Coast Health. Sydney, NSW (Australia).

Nady BRAIDY. BMedSci(Hons) DiplnnovMan

GradCertResMan MPharm. Faculty of Pharmacy,

University of Sydney. Sydney, NSW (Australia).

Khai BUI. BPharm DipHospPharm. Department of

Pharmacy, Ryde Hospital, Northern Sydney Central Coast Health Service. Sydney, NSW (Australia).
}

\author{
EVALUANDO EL IMPACTO DE LOS \\ NUEVOS ANTICOAGULANTES EN \\ AMBIENTE HOSPITALARIO
}

\section{RESUMEN}

Los defectos de los actuales anticoagulantes han llevado al desarrollo de nuevas y, a la vez más caras, alternativas orales.

Objetivo: Explorar el impacto potencial de los nuevos anticoagulantes dabigatran y rivaroxaban en el ambiente hospitalario local, en términos de utilización y subsiguiente coste.

Método: Se realizó un análisis de costes preliminar basado en una auditoria clínica prospectiva de 2 semanas (29 junio - 13 julio de 2009). Se extrajeron los datos relativos al manejo actual de la anticoagulación de las historias clínicas de los pacientes ingresados en el Hospital Ryde. Para modelizar implicaciones potenciales del uso de los nuevos agentes en el coste, se obtuvieron de los ensayos clínicos clave los datos de incidencia comunicada de tromboembolismo venososo/infarto y hemorragias.

Resultados: Se recogieron datos de 67 pacientes tratados o con warfarina $(n=46)$ o enoxaparina $(\mathrm{n}=21)$ para la profilaxis de TEV/infarto. Al menos dos tercios de todos los pacientes fueron considerados candidatos para el uso de los nuevos anticoagulantes orales (por tratamiento actual: warfarina: $65.2 \%$ (fibrilación), $34.8 \%$ (TEV); enoxaparina: $100 \%$, (TEV)). El uso de dabigatran para la prevención de TEV/infarto se vio más costeefectivo que la warfarina y la enoxaparina, debido a los significativamente menores costes de la monitorización y menores costes de administración. El rivaroxaban fue más coste-efectivo que la warfarina y la enoxiparina para prevención de TEV/infarto cuando se tuvieron en cuenta los descuentos del 33 del proveedor.

Conclusión: Este estudio ensalza la posible costeefectividad de los nuevos anticoagulantes dabigatran y rivaroxaban, comparados con warfarina y enoxiparina. Estos agentes pueden ofrecer ventajas económicas, así como beneficios clínicos, en el manejo hospitalario de pacientes anticoagulados.

Palabras clave: Anticoagulantes. Costes y Análisis de Coste. Australia. 


\section{INTRODUCTION}

Arterial and venous thromboses remain the major cause of mortality and morbidity in the developed world. $^{1,2}$ While arterial thrombosis has been directly associated with the development of myocardial infarction and stroke, venous emboli originate from deep vein thrombi in more than $95 \%$ of cases. ${ }^{1,2}$ These emboli are transported across large channels and generally pass through the right side of the heart and into the pulmonary vasculature to form fatal, pulmonary emboli. ${ }^{3-5}$ The coagulation pathway plays a pivotal role in the formation and progression of both arterial and venous thrombi. Therefore, drugs aimed at inhibiting this pathway are a major stratagem for the development of novel antithrombotic agents. ${ }^{6-8}$

Traditional anticoagulants such as warfarin, unfractionated heparin (UFH), and low-molecular weight heparins (LMWH) (e.g., enoxaparin, dalteparin, tinzaparin) have dominated the prevention and treatment of thromboembolic conditions such as myocardial infarction, stroke, and post-surgical thrombosis. ${ }^{6-9}$ While heparins are quick-acting intravenous or intramuscular preparations used over short periods in the hospital setting, warfarin is an oral Vitamin $\mathrm{K}$ antagonist that is suitable for long-term therapy. ${ }^{10-13}$ Although it is the only oral anticoagulant currently approved for widespread use, warfarin carries a number of limitations including: (1) slow onset of action; (2) the potential for genetic variation in metabolism; (3) multiple food and drug interactions; and (4) a narrow therapeutic index. Consequently, new "improved" anticoagulants, which demonstrate similar efficacy as warfarin but importantly with a better safety profile with respect to bleeding are highly sought-after. ${ }^{6-8}$

Selective newer, oral, anticoagulants which act on a single coagulation factor in the coagulation cascade have been recently developed. These include direct thrombin inhibitors such as dabigatran (Pradaxa ${ }^{\mathrm{TM}}$ ), and the factor $\mathrm{Xa}$ inhibitor, rivaroxaban (Xarelto ${ }^{\mathrm{TM}}$ ). ${ }^{\hat{9}}$ In contrast to the conventional multi-targeted antithrombotics such as warfarin and heparins, these agents have the potential to be much more effective, safer, and easier to use. .-9 $^{6-9}$

Dabigatran is an oral thrombin inhibitor that inactivates thrombin directly by binding to thrombin's active site and preventing its interaction with substrates. The drug offers a rapid onset of action compared to traditional anticoagulants. ${ }^{14,15} \mathrm{~A}$ phase II 'efficacy and safety' study has highlighted it's therapeutic benefits in prophylaxis of venous thromboembolism in patients undergoing orthopaedic surgery, where gastrointestinal complaints represented the most frequent adverse event. ${ }^{8,9}$ Dabigatran has also shown superiority over enoxaparin in two large phase III trials for prophylaxis of venous thromboembolism following total knee replacement and in patients undergoing total hip replacement. ${ }^{14,15}$ Moreover, dabigatran demonstrates that fixed doses of oral anticoagulants can indeed be used without the necessity for routine coagulation monitoring. ${ }^{6}$

Rivaroxaban is another selective inhibitor of factor $\mathrm{Xa}$ that has currently been approved for the prevention of thromboembolism in adult patients undergoing elective hip or knee replacement surgery. ${ }^{6-9,14-19}$ Traditionally, LMWHs (e.g., enoxaparin) and warfarin have been prescribed for the prevention of thromboembolism following orthopaedic surgery. ${ }^{6-9}$ However, intravenous/subcutaneous administration of LMWHs and the reduced safety profile for warfarin limit the ongoing use of these agents, making this alternative oral therapeutic a more convenient option for both the patients and clinicians. Rivaroxaban represents a highly potent and competitive factor $\mathrm{Xa}$ inhibitor that can inhibit fibrin-bound factor $\mathrm{Xa}$ with $\mathrm{a}$ significantly greater efficacy than fondaparinux when used at similar concentrations. ${ }^{20}$ In three phase III multicentre, double-blinded double dummy, randomised controlled trials, oral rivaroxaban $10 \mathrm{mg}$ demonstrated similar efficacy with intravenous enoxaparin $40 \mathrm{mg} .^{21}$ Additionally, the incidence of side effects did not differ between treatment groups in the same study. ${ }^{21}$

Direct thrombin inhibition, and inhibition of factor $\mathrm{Xa}$ represent novel approaches for the prevention and treatment of thromboembolism. ${ }^{6-9,16-19}$ However, their role in the management of hospitalised patients is unclear in terms of potential indications and the impact of this on hospital treatment costs, given that these agents are more expensive than those currently used. ${ }^{16-19}$ Therefore, the aim of this study was to evaluate the potential impact of the use of the new anticoagulants dabigatran and rivaroxaban in the local hospital setting for the prevention of venous thromboembolism (VTE) and stroke in patients with atrial fibrillation (SPAF), and subsequent estimate the costs involved.

\section{METHODS}

\section{Data Collection}

To evaluate the potential impact of dabigatran and rivaroxaban use in the local hospital setting, the costing analysis was designed to consider acute and long-term VTE and SPAF events, their longterm effects, prophylaxis-related side effects (eg. bleeding, deaths associated with VTE and SPAF), and other adverse reactions. A descriptive study was undertaken at a teaching hospital (Ryde Community Hospital, 170-beds) within the Sydney Northern Area Health Service comprising a prospective clinical audit conducted over a two week period (29th June -13th July 2009). The data collected was then used to undertaken a preliminary pharmaco-economic evaluation of the potential impact of using these agents in the hospital setting. A simplified cost-effectiveness analysis was undertaken to compare the costs and clinical outcomes of rivaroxaban, dabigatran, warfarin and enoxaparin for the prevention of VTE and stroke. Approval was obtained from the institutional Human Research Ethics Committee. 
Using purpose-designed forms, prospective data was collected on patients aged 18 years and above who had been admitted under the Geriatric Medicine, Orthopaedics and Cardiology wards and had been receiving either warfarin or enoxaparin during their hospital admission. Medical notes and drug charts were screened manually to identify patients on warfarin or enoxaparin and then to identify patients where oral rivaroxaban or dabigatran may be indicated. Data were also collected on patient characteristics, e.g. age, and gender, indications for anticoagulation, details of therapy, blood clotting test results (e.g. International Normalised Ratio, INR), incidence and severity of bleeding events, risk factors for adverse events including drug interactions and comorbidities.

\section{Decision Model}

The principal outcome measure was the incremental cost gained free from total venous thromboembolism (VTE) and stroke in patients with atrial fibrillation (SPAF). This end point was applied as the primary efficacy model in this study and was used to estimate the probability of VTE and stroke in patients, following orthopaedic surgery (hip and knee), and with atrial fibrillation, respectively (Figure 1A). A VTE could include proximal or distal DVT and could be symptomatic or non-symptomatic. A stroke could be symptomatic or immediately fatal. Symptomatic events were either detected by the patient at the hospital or were detected following discharge and therefore required readmission and/or outpatient treatment. Patients could also present with symptoms of VTE/stroke that were not confirmed, therefore resulting in additional cost increment associated with diagnostic procedures but had no significant effect on the patient outcome. Patients could also die following surgery from causes that were unrelated to either VTE or stroke (other post-surgical death).

Major bleeding events were incorporated into the study and included gastrointestinal, intracranial, or bleeding at surgical site so that the costs associated with these events could be accounted for. Patients with major bleeding could recover, die or be permanently disabled. Patients with minor bleeding events were assumed to recover (Figure 1B).

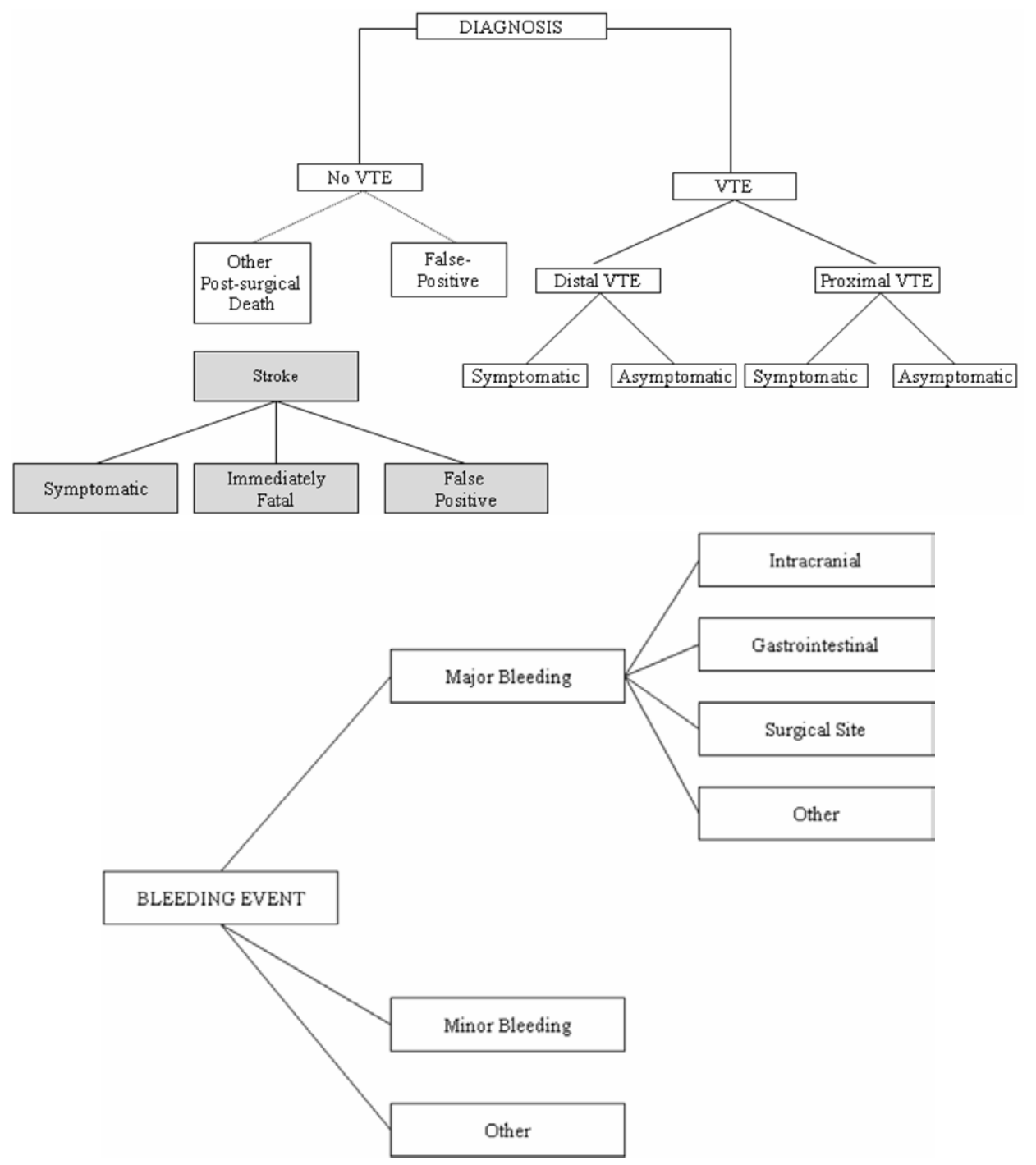

Figure 1: Schematic diagram of the model structure: (A) Model for VTE/SPAF; (B) Diagram of adverse reactions 


\section{Event Probabilities}

Data from subjects were used for the number of VTE events and SPAF due to warfarin and the number, type, and severity of bleeding events. The treatment of major bleeding events was modelled from review of the literature and data from the prospective audit. For dabigatran, the probability of VTE and/or SPAF, major and/or minor bleeding events were determined based on incidence of events in the total knee replacement (TKR) trial (RE-MODEL) and the total hip replacement (THR) trial (RE-NOVATE). For rivaroxaban, the probabilities of total VTE and/or SPAF and all-cause mortality, major and minor bleeding were calculated from the RECORD/PETRO trial. Probabilities for the new oral anticoagulants were quantified by assessing the relative risk for each end point, compared to the probabilities in the warfarin and enoxaparin arm.

\section{Patient Population}

The impact of new anticoagulants were modelled separately to reflect differences in the incidence of venous thromboembolism (VTE), and stroke in patients with atrial fibrillation (SPAF), age and gender distribution, and duration of VTE and SPAF prophylaxis. The mean age of patients incorporated into the model was 81.5 years for VTE and 83.5 years for SPAF. Subgroup analysis was performed by age, gender, and risk factors for VTE and SPAF.

\section{Resource Use and Cost Estimation}

Following the identification of patients prescribed anticoagulants, the potential costs associated with the transition to the newer agents were calculated. Cost-effectiveness and benefit-to-risk profiles are a common method for determining the resource costs incurred in achieving a predefined clinical outcome. While several perspectives may be adopted, this evaluation has considered the view of the third-party payer (the Pharmaceutical Benefits Scheme [PBS]) and has calculated only direct costs.

The cost of year of analysis was 2009. The costs of giving dabigatran or rivaroxaban to prevent VTE and SPAF assumed the mean duration of prophylaxis in VTE and SPAF under the Australian Therapeutics Guidelines (2009). ${ }^{22}$ Drug costs were taken from the Australian Pharmaceutical Benefits Scheme, July 2008. ${ }^{23}$ Additionally, the cost for rivaroxaban included a $33 \%$ supplier-rebate based on a pricing submission to the hospital for its supply. Time for the administration of warfarin included 20 minutes of nurse time to check INRs and to administer the drug. The administration costs for enoxaparin included time to administer injection and to counsel outpatients on self-injection following discharge. The associated costs were calculated from the nurse hourly rates from Australian public health data (2007-2008). ${ }^{24}$ Administration costs for dabigatran and rivaroxaban included 10 minutes of nursing time to retrieve the dose of medication.

The anticoagulant effect of dabigatran can be measured by ecarin clotting time and thrombin time. Similarly, rivaroxaban may be monitored by measuring factor Xa activity as well as prothrombin time. However, such tests have not been widely used in association with dabigatran and rivaroxaban therapy. While they are potentially advantageous, regular testing of alanine aminotransferase (ALT) levels has been recommended at baseline and monthly for the first 6 months of commencing therapy, every second month for the remainder of the first year, and every third month thereafter, as a safety precaution. ${ }^{14,15}$ Given that all patients admitted to hospital will receive a liver function test which measures ALT as part of their standard assessment, only the cost of the second test was included as part of long-term monitoring and followup. The cost of conducting ALT testing was determined accordingly and derived from the Medicare Benefits Schedule, July 2009. ${ }^{25}$ Monitoring costs in conducting INR tests for warfarin patients was derived from the Medicare Benefits Schedule July $2009 .^{25}$ No monitoring tests were included for enoxaparin since the dose is calculated according to the specific weight and renal function of each individual patient, as recommended by the Australian Therapeutic Guidelines (2009). ${ }^{23}$

The length of stay for confirmed cases of VTE and atrial fibrillation (AF) was modelled for data from the prospective audit. A weighted average of the incremental mean length of stay was determined (8.5 days for VTE, 12.5 days for AF). The cost associated with the length of stay was estimated using a per diem cost for each ward. The cost of a hospital admission due to a major bleeding event was based on 2007-2008 Australian public hospital data. Clinically relevant minor bleeding events were estimated as two outpatient visits and were based on clinical opinion, as has been previously described. $^{26}$

\section{Analysis}

Given that the basic analysis adopts a modelling approach, it was sensible to apply a sensitivity analysis to judge how robust the results were based on assumptions made. The following data were subjected to sensitivity analysis: (1) cost of monitoring anticoagulation; (2) length of stay for bleeding events; (3) percentage of patients admitted to the hospital for a bleeding event; (4) percentage of patients discharged to hospital continuing care; (5) unit costs for hospital bed-days; and (6) incidence of bleeding events in NSW.

A cost minimisation analysis was applied to determine cost differences between each anticoagulant therapy given that the incidence of VTE/SPAF and bleeding events were equivalent in each treatment group.

\section{RESULTS}

In total, over the 2-week clinical audit, 67 patients were identified from the orthopaedic and coronary care units who had VTE or SPAF and were administered warfarin $5 \mathrm{mg}$ once daily $(n=46)$ or enoxaparin $40 \mathrm{mg}$ intravenously once daily $(n=21)$ (the approved doses in patients for the prevention of VTE or SPAF in Australia). Baseline characteristics were well matched between the treatment groups for each traditional anticoagulant (Table 1). Of the 


\begin{tabular}{|c|c|c|}
\hline & \multicolumn{2}{|c|}{ All Participants } \\
\hline & Warfarin 5mg Once Daily $(n=46)$ & Enoxaparin $40 \mathrm{mg}$ Once Daily $(\mathrm{n}=21$ \\
\hline Age (years) & $79.19(10.3)$ & $78.13(12.19)$ \\
\hline Men & $38(82.6 \%)$ & $15(71.4)$ \\
\hline Weight & $82.10(19.61)$ & $83.50(21.12)$ \\
\hline BMI $\left(\mathrm{kg} / \mathrm{m}^{2}\right) *$ & $30.10(5.3)$ & $29.30(5.8)$ \\
\hline Creatinine Clearance (mL/min) & $41.56(8.39)$ & $65.22(12.81)$ \\
\hline \multicolumn{3}{|l|}{ Medical History } \\
\hline Previous MI & $35(76.09 \%)$ & $10(47.62 \%)$ \\
\hline Hypertension & $25(54.35 \%)$ & $8(38.10 \%)$ \\
\hline Diabetes & $19(41.30 \%)$ & $6(28.57 \%)$ \\
\hline Dyslipidemia & $21(45.65 \%)$ & $8(38.10 \%)$ \\
\hline Smoker & $12(26.09 \%)$ & $6(28.58 \%)$ \\
\hline \multicolumn{3}{|l|}{ Drugs } \\
\hline Aspirin & $29(63.04 \%)$ & $10(47.62 \%)$ \\
\hline$\beta$-Blocker & $21(45.65 \%)$ & $8(38.10 \%)$ \\
\hline ACE-I or ARB & $34(74.91 \%)$ & $12(57.14 \%)$ \\
\hline Statin & $21(45.65 \%)$ & $8(38.10 \%)$ \\
\hline CCB & $18(39.1 \%)$ & $6(28.57 \%)$ \\
\hline \multicolumn{3}{|l|}{ Indication for New Anticoagulant } \\
\hline SPAF & $30(65.22 \%)$ & $0(0 \%)$ \\
\hline VTE & $16(34.78 \%)$ & $21(100 \%)$ \\
\hline \multicolumn{3}{|c|}{$\begin{array}{l}\text { Excluded because new anticoagulant is } \\
\text { contraindicated }\end{array}$} \\
\hline Renal Dysfunction & $2(4.35 \%)$ & $1(4.76 \%)$ \\
\hline Uncontrolled hypertension & $1(2.17 \%)$ & $1(4.76 \%)$ \\
\hline Gl bleed in past 6 months & $1(2.17 \%)$ & $1(4.76 \%)$ \\
\hline Hepatic Impairment & $3(6.52 \%)$ & $2(9.53 \%)$ \\
\hline
\end{tabular}

\begin{tabular}{|l|c|c|c|c|}
\hline \multicolumn{6}{|l|}{ Table 2. Incidence and cost of total major bleeding events with warfarin and enoxaparin. } \\
\hline Major Bleeding Events & Intracranial & Surgical Site & Gastrointestinal & Other \\
\hline No. of Bleeding Events & $1(1.82 \%)$ & $2(3.62 \%)$ & $3(5.45 \%)$ & $2(3.64 \%)$ \\
\hline Survivor Permanently Disabled & $1(1.82 \%)$ & 0 & 0 & \\
\hline Cost (\$AUS) & & & & 7260 \\
\hline Acute Care & 2420 & 4840 & 0 & 0 \\
\hline Long-term Care & 8712 & 0 & & 0 \\
\hline
\end{tabular}

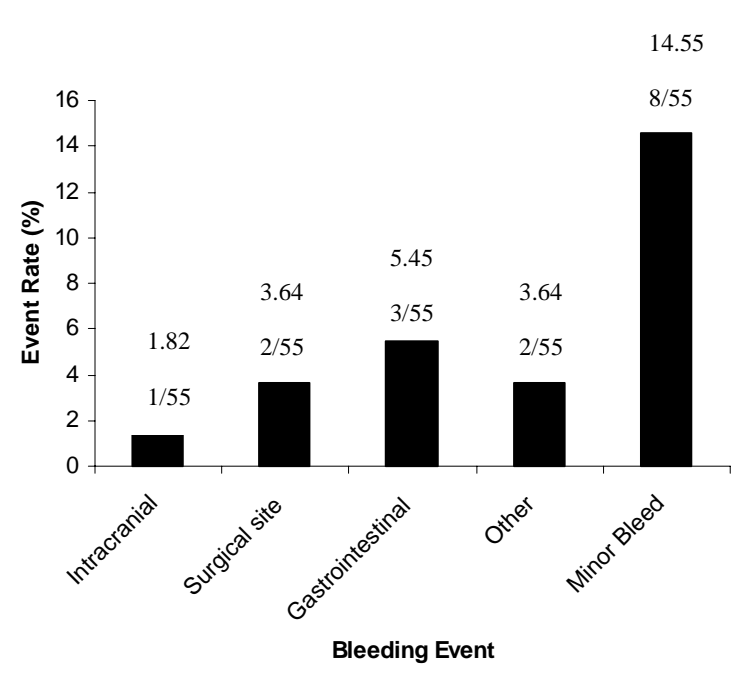

Figure 2. Incidence of major bleeding events with warfarin and enoxaparin.

participants, 6 patients were excluded in the warfarin group and 5 patients were excluded in the enoxaparin group. The reasons for exclusion included poor renal function, uncontrolled hypertension, Gl bleed in the last 6 months, hepatic impairment, and were similar in the dabigatran and rivaroxaban groups within the RE-MODEL/RE-
NOVATE and RECORD/ATLAS ACS-TMI 46 trials respectively.

Participants in the warfarin group had a higher prevalence of myocardial infarction $(p<0.05)$, hypertension $(p<0.05)$, diabetes $(p<0.05)$ and dyslipidemia $(p<0.05)$, compared to the enoxaparin treatment group. In the warfarin group, a significantly higher majority of patients were treated concomitantly with aspirin $(p<0.05)$, angiotensinconverting enzyme (ACE) inhibitor or angiotension2 receptor blocker $(A R B)(p<0.05)$, statins, calcium channel blockers (CCB) $(p<0.05)$ than the enoxaparin group. A significant proportion of patients were administered warfarin for SPAF compared to VTE $(p<0.05)$. All patients in the enoxaparin group were administered the drug as a prophylaxis of VTE.

Table 2 and Figure 2 provide the major bleeding events for the entire study population in both warfarin and enoxaparin treated patients. The incidence of major bleeds is categorised by type of bleeding event (e.g. intracranial, surgical site or gastrointestinal), and the cost of resolving these events to the healthcare system. Gastrointestinal bleeds were the most common types of bleeding $(5.45 \%)$, followed by bleeding at the surgical site $(3.62 \%)$. Intracranial bleeds were least common and accounted for $1.8 \%$ of the study population with significantly higher cost for long term care. Other bleeds accounted for $3.6 \%$. 


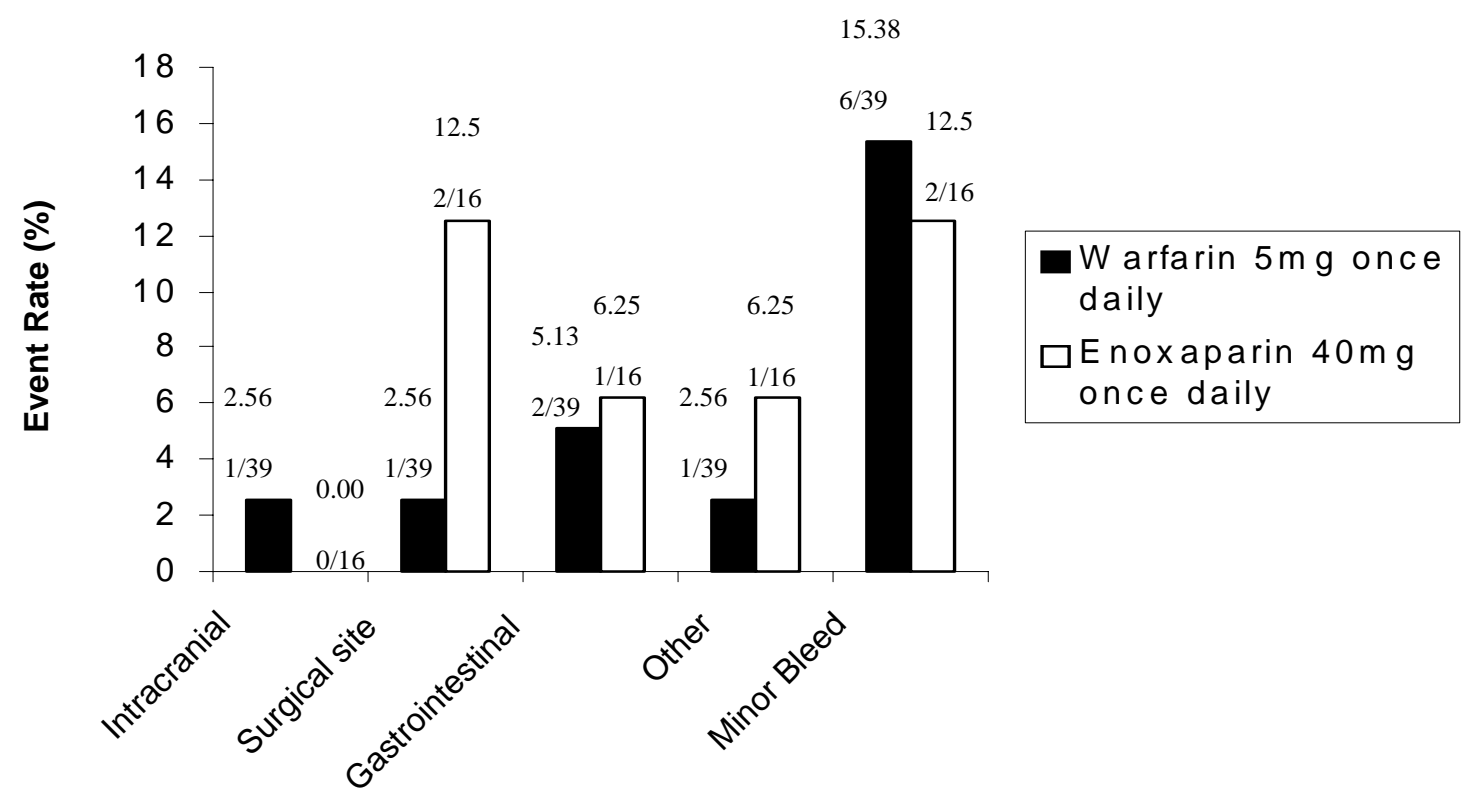

Bleeding Event

Figure 3. Incidence of major and minor bleeding events with warfarin and enoxaparin

\begin{tabular}{|c|c|c|c|c|c|c|c|c|}
\hline \multirow{2}{*}{ Cost of Prophylaxis } & \multicolumn{2}{|c|}{$\begin{array}{c}\text { Warfarin } 5 \mathrm{mg} \\
\text { Once Daily }(n=39)\end{array}$} & \multicolumn{2}{|c|}{$\begin{array}{l}\text { Enoxaparin } 40 \mathrm{mg} \\
\text { Once Daily }(\mathrm{n}=16)\end{array}$} & \multicolumn{2}{|c|}{$\begin{array}{c}\text { Dabigatran } 220 \mathrm{mg} \\
\text { Once Daily }\end{array}$} & \multicolumn{2}{|c|}{$\begin{array}{c}\text { Rivaroxaban } 10 \mathrm{mg} \\
\text { Once Daily }\end{array}$} \\
\hline & VTE & SPAF & VTE & SPAF & VTE & SPAF & VTE & SPAF \\
\hline $\begin{array}{l}\text { No. of doses received } \\
\text { during admission (SD) }\end{array}$ & $\begin{array}{l}10.44 \\
(1.9)\end{array}$ & $\begin{array}{l}9.66 \\
(1.5)\end{array}$ & $\begin{array}{l}16.01 \\
(2.1) \\
\end{array}$ & 0 & $7.7(1.3)$ & $\begin{array}{l}12.2 \\
(1.8) \\
\end{array}$ & 8.8 & 15.17 \\
\hline $\begin{array}{l}\text { Cost of drug per day } \\
\text { (AUD) }\end{array}$ & 5.85 & 5.85 & 6.12 & 6.12 & 8.87 & 8.87 & 4.27 & 4.27 \\
\hline \multicolumn{9}{|l|}{$\begin{array}{l}\text { Administration Costs } \\
\text { per day (AUD) }\end{array}$} \\
\hline Inpatient & 10.35 & 10.35 & 15.40 & 0 & 5.18 & 5.18 & 5.18 & 5.18 \\
\hline Outpatient & 0 & 0 & 5.44 & 0 & 0 & 0 & 0 & 0 \\
\hline $\begin{array}{l}\text { Cost per patient } \\
\text { (AUD) }\end{array}$ & 71.42 & 66.86 & 118.86 & 0 & 73.49 & 113.39 & 42.74 & 69.94 \\
\hline
\end{tabular}

\begin{tabular}{|c|c|c|c|c|c|c|}
\hline \multirow{3}{*}{ Cost of Monitoring } & \multirow{2}{*}{\multicolumn{2}{|c|}{$\begin{array}{c}\text { Warfarin 5mg Once Daily } \\
(\mathrm{n}=39) \\
\mathrm{INR}^{26}\end{array}$}} & \multirow{2}{*}{\multicolumn{2}{|c|}{$\begin{array}{c}\text { Dabigatran 220mg Once Daily } \\
\mathrm{ALT}^{26, !}\end{array}$}} & \multicolumn{2}{|c|}{ Rivaroxaban 10mg Once Daily } \\
\hline & & & & & & \\
\hline & VTE & SPAF & VTE & SPAF & VTE & SPAF \\
\hline $\begin{array}{l}\text { No. of tests conducted } \\
\text { during admission (SD) }\end{array}$ & $3.23(1.44)$ & $3.71(1.59)$ & 2 & 2 & 2 & 2 \\
\hline $\begin{array}{l}\text { Cost of test per day } \\
\text { (AUD) }\end{array}$ & 13.80 & 13.80 & 9.75 & 9.75 & 9.75 & 9.75 \\
\hline Cost per patient (AUD) & 44.57 & 51.20 & 9.75 & 9.75 & 9.75 & 9.75 \\
\hline
\end{tabular}

\begin{tabular}{|c|c|c|c|c|c|c|c|c|c|c|}
\hline \multirow[b]{2}{*}{ Efficacy } & \multicolumn{2}{|c|}{$\begin{array}{l}\text { RR, Dabigatran vs } \\
\text { Warfarin }(95 \% \mathrm{Cl})^{27}\end{array}$} & \multicolumn{2}{|c|}{$\begin{array}{l}\text { RR, Dabigatran } \\
\text { vs Enoxaparin } \\
(95 \% \mathrm{Cl})^{30}\end{array}$} & \multicolumn{2}{|c|}{$\begin{array}{l}\text { RR, Rivaroxaban vs } \\
\text { Warfarin }(95 \% \mathrm{Cl})^{31}\end{array}$} & \multicolumn{2}{|c|}{$\begin{array}{l}\text { RR, Rivaroxaban } \\
\text { vs Enoxaparin } \\
(95 \% \mathrm{Cl})^{32}\end{array}$} & \multicolumn{2}{|c|}{$\begin{array}{l}\text { Incidence } \\
(\% \mathrm{n} / \mathrm{N})^{29-32}\end{array}$} \\
\hline & VTE & Stroke & VTE & Stroke & VTE & Stroke & VTE & Stroke & VTE & Stroke \\
\hline $\begin{array}{l}\text { Total VTE/stroke } \\
\text { and all-cause } \\
\text { mortality }\end{array}$ & $\begin{array}{c}0.94 \\
(0.76- \\
1.85)\end{array}$ & $\begin{array}{c}0.88 \\
(0.58- \\
1.39)\end{array}$ & $\begin{array}{c}0.97 \\
(0.83- \\
1.13)\end{array}$ & - & $\begin{array}{l}0.71 \\
(0.55- \\
2.33)\end{array}$ & $\begin{array}{c}0.80 \\
(0.60- \\
1.05)\end{array}$ & $\begin{array}{l}0.68 \\
(0.71- \\
5.67)\end{array}$ & - & $\begin{array}{c}37.7 \\
(193 / 51 \\
2)\end{array}$ & $\begin{array}{c}3.9 \\
(87 / 2331 \\
)\end{array}$ \\
\hline
\end{tabular}




\begin{tabular}{|c|c|c|c|c|c|c|c|c|c|c|}
\hline & \multicolumn{2}{|c|}{$\begin{array}{l}\text { RR, Dabigatran vs } \\
\text { Warfarin }(95 \% \mathrm{Cl})\end{array}$} & \multicolumn{2}{|c|}{$\begin{array}{c}\text { RR, Dabigatran vs } \\
\text { Enoxaparin }(95 \% \\
\text { Cl) }\end{array}$} & \multicolumn{2}{|c|}{$\begin{array}{l}\text { RR, Rivaroxaban } \\
\text { vs Warfarin }(95 \% \\
\text { CI) })^{[31]}\end{array}$} & \multicolumn{2}{|c|}{$\begin{array}{c}\text { RR, Rivaroxaban } \\
\text { vs Enoxaparin } \\
(95 \% \mathrm{Cl})^{[32]}\end{array}$} & \multicolumn{2}{|c|}{$\begin{array}{c}\text { Incidence } \\
(\% \mathrm{n} / \mathrm{N})^{[29-32]}\end{array}$} \\
\hline Safety & VTE & SPAF & VTE & SPAF & VTE & SPAF & VTE & SPAF & VTE & SPAF \\
\hline $\begin{array}{l}\text { Major bleeding } \\
\text { Event }\end{array}$ & $\begin{array}{c}1.5 \\
(0.81- \\
4.52)\end{array}$ & $\begin{array}{c}0.82 \\
(0.65- \\
2.38)\end{array}$ & $\begin{array}{r}1.35 \\
(0.46- \\
2.78)\end{array}$ & - & $\begin{array}{l}1.33 \\
(0.71- \\
5.69)\end{array}$ & $\begin{array}{c}0.68 \\
(0.41- \\
1.28)\end{array}$ & $\begin{array}{l}1.14 \\
(0.71- \\
3.52)\end{array}$ & - & $\begin{array}{c}1.3 \\
(9 / 694 \\
\end{array}$ & $\begin{array}{c}0.1 \\
(1 / 901)\end{array}$ \\
\hline $\begin{array}{l}\text { Minor } \\
\text { Event }\end{array}$ & $\begin{array}{l}1.86 \\
(0.64- \\
2.26)\end{array}$ & $\begin{array}{l}0.84 \\
(0.91- \\
3.46)\end{array}$ & $\begin{array}{l}1.04 \\
(0.82- \\
1.33)\end{array}$ & - & $\begin{array}{l}1.41 \\
(0.75- \\
3.48)\end{array}$ & $\begin{array}{l}0.44 \\
(0.39- \\
2.27)\end{array}$ & $\begin{array}{l}1.12 \\
(0.81- \\
2.35)\end{array}$ & - & $\begin{array}{c}15.3 \\
(106 / 6 \\
94)\end{array}$ & $\begin{array}{c}0.2 \\
(2 / 901)\end{array}$ \\
\hline
\end{tabular}

\begin{tabular}{|l|c|c|c|c|}
\hline Table 7. Cost-effectiveness analysis of dabigatran and rivaroxaban versus warfarin and enoxaparin in VTE and SPAF \\
\hline Cost Difference & $\begin{array}{c}\text { Dabigatran vs } \\
\text { Warfarin }\end{array}$ & $\begin{array}{c}\text { Dabigatran vs } \\
\text { Enoxaparin }\end{array}$ & $\begin{array}{c}\text { Rivaroxaban vs } \\
\text { Warfarin }\end{array}$ & $\begin{array}{c}\text { Rivaroxaban vs } \\
\text { Enoxaparin }\end{array}$ \\
\hline VTE & Dabigatran Dominant & Dabigatran Dominant & Rivaroxaban Dominant & Rivaroxaban Dominant \\
\hline SPAF & Dabigatran Dominant & - & Rivaroxaban Dominant & - \\
\hline
\end{tabular}

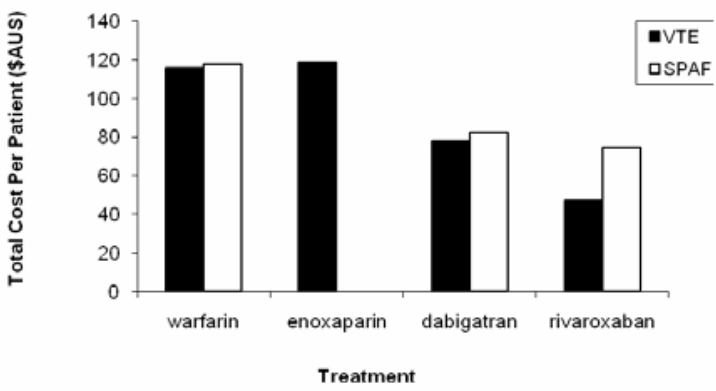

Figure 4. Total cost of anticoagulation therapy over total period of hospitalisation per patient for VTE and SPAF

Figure 3 provides the percentage of total bleeding events in both warfarin and enoxaparin treatment groups. There was no heterogeneity in the rates of bleeding between warfarin and enoxaparin groups. One patient in the warfarin group presented with intracranial haemorrhage and required long-term management. Major bleeding at the surgical site was significantly greater in enoxaparin participants compared to the warfarin group $(P<0.05)$. No significant difference was observed for the rate of gastrointestinal and other major bleeds, and minor bleeds in patients given warfarin compared with enoxaparin.

If new anticoagulants are to be considered as potential replacements for warfarin and/or enoxaparin for preventing VTE's or stroke associated with atrial fibrillation, drug cost is a critical issue. To determine the potential cost benefits for dabigatran and rivaroxaban compared to traditional anticoagulants, the cost of using these newer anticoagulants was compared to the cost of warfarin and enoxaparin for VTE and SPAF respectively (Table 3$)$. The costs of warfarin $(5 \mathrm{mg}$ once daily) and enoxaparin (40mg once daily) for these indications is AUD5.85 and AUD6.12 per day, respectively. The cost of dabigatran $(220 \mathrm{mg}$ once daily) was significantly higher compared to traditional anticoagulants at AUD8.87. The cost of rivaroxaban (10mg once daily) was significantly lower than for the traditional anticoagulants, at AUD4.27 after a 33\% rebate under a supplier agreement. This represents the best available estimates for the costs of using dabigatran and rivaroxaban, although the dose might vary for VTE and SPAF depending on patient's renal and hepatic function. The cost of prophylaxis was significantly higher for warfarin and enoxaparin compared to dabigatran and rivaroxaban (Table 3). The costs for enoxaparin were higher due to the cost of nursing time for administration of subcutaneous injections during inpatient stay and the cost of administration after discharge. Administration costs included the cost of nursing time for frequent and accurate monitoring of INR levels in inpatients and dosage retrieval for dabigatran and rivaroxaban. The reduced cost of dabigatran was due to repackaging the half-dose given on the first day of prophylaxis. The cost of rivaroxaban was significantly lower than warfarin and enoxaparin, primarily due to supplierrebates.

Routine monitoring of warfarin (i.e. international normalised ratio -INR) is a standard guideline for the prophylaxis of VTE and SPAF. The cost of monitoring anticoagulation was significantly higher for warfarin (AUD44.57 and AUD51.20 respectively) compared to dabigatran (AUD9.75) and rivaroxaban (AUD9.75) (Table 4). While the cost per test for INR is only slightly higher than the cost of ALT test, the cost difference is attributed to the greater frequency of monitoring of INR levels compared to ALT testing (Table 4). No monitoring costs were included for enoxaparin.

The results for the efficacy of anticoagulation are presented in Table 5. The outcomes were comparable for patients receiving warfarin, enoxaparin, dabigatran or rivaroxaban in both the VTE and SPAF analysis. Although the incidence of VTE/SPAF was slightly lower for dabigatran and rivaroxaban compared to warfarin and enoxparin, the differences in efficacy were small (Table 5). Although the incidence of bleeding events (including major and minor bleeds) was slightly higher for dabigatran and rivaroxaban compared to warfarin and enoxaparin, it did not reach statistical significance (Table 6). Altogether, these results reflect a similar efficacy and safety profile as for the new anticoagulants in the RE-MODEL/RE-NOVATE and RECORD/PETRO trials, respectively. 
In patients undergoing prophylaxis for VTE and SPAF, dabigatran was dominant over warfarin and enoxaparin in terms of cost of drug administration and therapeutic monitoring, and efficacy and safety of the anticoagulant therapy (Figure 4 and Table 7). Similarly, rivaroxaban was dominant over warfarin and enoxaparin for the prophylaxis of VTE and SPAF. While the cost of therapeutic monitoring is significantly reduced for rivaroxaban compared to warfarin, the presence of existing supplier-rebates further reduces the costs of using this newer agent, compared to the costs of warfarin and enoxaparin which maintain similar efficacy and safety profiles.

\section{DISCUSSION}

VTE and stroke are extremely common and often fatal conditions, yet there are poorly managed due to limited treatment option. Not surprisingly, this has led to the development of newer anticoagulants. Traditionally, warfarin has been used in the hospital setting for the prophylaxis of VTE and SPAF. ${ }^{32}$ However, it has several other shortcomings, including: (1) the need for frequent therapeutic monitoring, which is a considerable inconvenience to the patient and a significant cost burden on the healthcare system ${ }^{33,34}$; (2) INR levels are significantly affected by foods and herbs, adding to the difficulty of maintaining dosage regimens ${ }^{35}$; (3) apart from Gl bleeding, warfarin may also cause haemorrhagic stroke, osteoporosis and bone fracture (long-term use) and other debilitating complications $^{36,37}$; and (4) warfarin can interact with at least 60 commonly administered drugs including paracetamol and can be as fatal as elevating INR to 6.0 or higher. ${ }^{38}$ LMWH's such as enoxaparin are also effective at preventing coagulation but are less commonly used due to the need for administration by injection. ${ }^{29}$ Concerted efforts to find alternative anticoagulants have led to the development of the new oral anticoagulants, dabigatran and rivaroxaban.

Dabigatran and rivaroxaban have been previously reported to have comparable efficacy and similar safety profiles compared to warfarin and enoxaparin. ${ }^{28-31}$ The current study results indicate that dabigatran may be cost effective compared to warfarin and enoxaparin for use in patients undergoing prophylaxis for VTE and SPAF, respectively. In VTE and SPAF patients, cost parameters and outcomes were similar for these anticoagulants. Modest cost savings were expected for dabigatran for the prevention of VTE since it can provide oral anticoagulant therapy without the need for dose adjustment or routine coagulation monitoring. In SPAF patients given warfarin, and in whom long-term prophylaxis is necessary, estimated cost savings are more substantial. Moreover, monitoring in some countries is by the physician or pharmacist and warfarin monitoring costs would therefore be higher than the costs presented in this study. These findings are consistent with a similar study by the United Kingdom (UK) Health Service, whereby dabigatran was found to be cost-effective compared with the dose of enoxaparin approved for use in patients undergoing orthopaedic surgery in the UK. ${ }^{26}$

Moreover, the longer half-life of dabigatran makes it an ideal agent for stroke prevention. The RE-LY (Randomized Evaluation of Long-Term Anticoagulation Therapy) evaluated the effect of two doses of dabigatran (150 and $110 \mathrm{mg}$ ) for SPAF relative to warfarin. ${ }^{39,40}$ While higher doses were superior to warfarin for stroke prevention, similar efficacy to warfarin was observed at lower doses. Although no difference in bleeding rates were reported for warfarin compared to higher doses of dabigatran, lower doses were associated with lower incidence of bleeding events. ${ }^{39,40}$ This may further direct the cost-efficacy results in the favour of dabigatran.

Similarly, rivaroxaban was found to be more costeffective compared to warfarin and enoxaparin in the current study. On the basis of the pharmacology and the findings of this study and others, treatment with rivaroxaban might become a useful adjunct to therapy in patients for the prophylaxis of VTE and/or SPAF. As previously mentioned, its oral route of administration, low pharmacological dose, and timing of administration are more advantageous compared to warfarin and enoxaparin. Moreover, under a plausible set of assumptions, the reduced cost of rivaroxaban make it more cost effective compared to traditional anticoagulant therapy.

Several other phase III trials, such as MAGELLAN and EINSTEIN are currently examining the impact of rivaroxaban in other clinical settings such as pulmonary embolism. ${ }^{41,42}$ If rivaroxaban is found to be more efficacious than traditional anticoagulants, then it may replace warfarin and/or enoxaparin for initial and acute therapy as well as for long-term care. The ROCKET study is aimed at comparing a fixed dose of rivaroxaban in AF and SPAF compared to standard warfarin treatment. ${ }^{43}$ ATLAS TMI 5 is also evaluating the effectiveness of rivaroxaban for the treatment of acute coronary syndrome. ${ }^{44}$ Results of both studies are expected to be released in 2011. Other factor Xa inhibitors have been developed for the prevention of VTE, for which warfarin, has long been the first choice. Apixaban is being tested to prevent DVT and pulmonary embolism that sometimes occur within patients hospitalized for acute medical illness (ADOPT). ${ }^{45}$ These studies are almost complete and will likely to be published in the coming months. The use of new oral anticoagulants poses several benefits over warfarin and enoxaparin for the prophylaxis of VTE and stroke. Firstly, the oral route of administration significantly reduces the need for self-administration in outpatients prescribed enoxaparin, or the need for further healthcare requirements in patients unable to self-inject following hospital discharge. ${ }^{39}$ These issues limit the use of enoxaparin for extended prophylaxis. Other costs that may be reduced include the cost of platelet monitoring for HITs, needle stick injuries and disposal of sharps. ${ }^{39}$ Newer oral anticoagulants may also improve patient compliance due to reduced need for frequent monitoring and dosage adjustments, or may prefer 
oral medications rather than subcutaneous injections. $^{39}$

In the present study, modelling was necessary to estimate the incidence and impact of VTE/SPAF and bleeding events. While the model parameters were validated by feedback from clinical experts, like all models, assumptions about these may affect the final results. For instance, when a single patient experienced more than one event during their hospital admission, (e.g. VTE and/or stroke, and bleeding events), the costs of managing the patient were assumed to be additive. Moreover, the incidence of VTE/SPAF from the descriptive data indicated that the probability of having at least one event during the study period and does not reflect the possibility of multiple events occurring in an individual (e.g VTE and stroke). In addition, the current study does not include additional costs associated with platelet monitoring for heparin induced thrombosis (HITs), possible needle-stick injuries or the disposal of sharps. The study does not include potential utility costs such as avoidance of daily enoxaparin injection. Therefore, the cost effectiveness for dabigatran and rivaroxaban may be underestimated when compared to enoxaparin. ${ }^{39}$

Furthermore, the current study was carried out over a very short two-week period based on the perspective of Ryde Community Hospital, which is a community teaching hospital with limited number of beds. Therefore, the number of patients able to be included in the warfarin/enoxaparin arm is small. Therefore, there are limitations with applying the drug costs involved here to other healthcare facilities operating under different contracts or health systems internationally, and where the number of patients hospitalised may be much greater than in the present study.

While the cost of life is not included in the current analysis, the cost efficacy may likely to be improved, given the lower mortality of dabigatran and rivaroxaban over warfarin and enoxaparin for the treatment of VTE/SPAF. Using data collected from the RE-LY trial and other published studies of anticoagulation, Freeman et al (2010) recently showed that dabigatran can improve the quality of life of patients with SPAF compared to traditional adjusted-dose warfarin in the United Kingdom. ${ }^{46}$ Similarly, rivaroxaban was shown to be more costeffective compared to enoxaparin for the treatment of VTE in the Irish hospital setting. It remains uncertain whether dabigatran is more cost effective than rivaroxaban when compared to warfarin or enoxaparin, using the same strategy. ${ }^{47}$

\section{CONCLUSION}

In conclusion, this study highlights the potential cost-effectiveness of newer anticoagulants, dabigatran and rivaroxaban, compared to warfarin and enoxaparin. These agents may offer economic advantages, as well as clinical benefits, in the hospital-based management of anticoagulated patients.

\section{CONFLICT OF INTEREST}

The authors have no conflicts of interest to declare.

\section{References}

1. Agostoni E, Aliprandi A, Longoni M. Cerebral venous thrombosis. Expert Rev Neurother. 2009;9(4):553-564.

2. Serebruany V, Makarov L. Praugrel for arterialcoronary thrombosis. Drugs Today (Barc). 2009;45(2):83-91.

3. Pelletier M, Bugeaud R, Ibrahim R, Morency G, Kouz S. Successful thrombolysis of a stroke with a pulmonary embolism in young woman. J Emerg Med. 2010;39(4):443-448.

4. Bhatia V, Arora P, Parida AK, Singh G, Kaul U. Air travel and pulmonary embolism: "economy class syndrome". Indian Heart J. 2008;60(6):608-611.

5. Konstantinides S. Clinical practice, acute pulmonary embolism. N Engl J Med. 2008;359(26):2804-2813.

6. Bauer KA. New anticoagulants. Curr Opin Hematol. 2008;15(5):509-515.

7. Bauer KA. New anticoagulants. Hematology Am Soc Hematol Educ Program. 2006;450-456.

8. Haideri N, Patel H. New anticoagulents \& clinical trials. Mo Med. 2009;106(1):60-64.

9. Khoo CW, Tay KH, Shantsila E, Lip GY. Novel oral anticoagulents. Int J Clin Pract. 2009;63(4):630-641.

10. Dentali F, Crowther MA. Management of excessive anticoagulant effect due to vitamin $\mathrm{K}$ antagonists. Hemtaology Am Soc Hematol Educ Program. 2008;266-270.

11. Fang MC. Antithrombotic therapy for the treatment of atrial fibrillation in the elderly. J Interv Card Electrophysiol. 2009;25(1):19-23.

12. Uncu H. A comparison of low-molecular-weight heparin and combined therapy of low-molecular-weight heparin with an anti-inflammatory agent in the treatment of superficial vein thrombosis. Phlebology. 2009;24(2):56-60.

13. Alban S. Pharmacology of heparins and direct anticoagulants. Hamostaseologie. 2008;28(5):400-420.

14. Olsson SB. Stroke prevention with the oral direct thrombin inhibitor ximelagatron compared with warfarin in patients with non-valvular atrial fibrillation (SPORTIF-III): randomised controlled trial. Lancet. 2003;362:1691-1698.

15. Walenga JM, Jeske WP, Samama MM, Frapaise FX, Bick RL, Fareed J. Fondaparinux: a synthetic heparin pentasaccharide as a new antithrombotic agent. Expert Opin Investig Drugs. 2002;11(3):397-407.

16. Weitz JI, Hirsh J. New anticoagulant drugs. Chest. 2001;119:95S-107S.

17. Graff J, von Hentig N, Misselwitz F, Kubitza D, Becka M, Breddin Hans-Klaus, Harder S. (2007). Effects of the oral, direct factor $\mathrm{Xa}$ inhibitor Rivaroxaban on platelet-induced thrombin generation and prothrombinase activity. J Clin Pharmacol. 2007;47:1398. 
18. Bayer plc. Xarelto $10 \mathrm{mg}$ film-coated tablets. Electronic Medicines Compendium. 2008. http://emc.medicines.org.uk/ (Accessed 04/2009)

19. Haas S. New anticoagulants - towards the development of an "ideal" anticoagulant. Vasa. 2009;38(1):13-29.

20. Depasse FBJ, Mnich J, Le Flem L, Gerotziafas GT, Samama MM. Effect of BAY 59-7939-a novel, oral, direct factor Xa inhibitor-on clot-bound factor Xa activity in vitro. Presented at XXth Congress of the International Society on Thrombosis and Homeostasis; August 6-12, 2005; Sydney Australia.

21. Lassen MR, Ageno W, Borris LC, Lieberman JR, Rosencher N, Bandel TJ, Misselwitz F, Turpie AG; RECORD3 Investigators. Rivaroxaban versus enoxaparin for thromboprophylaxis after total knee arthroplasty. $\mathrm{N}$ Engl J Med. 2008;358: 2776-2786.

22. Therapeutic Guidelines: Cardiovascular. Version 4. Melbourne: Therapeutic Guidelines Limited; 2003.

23. Medicare Australia Annual Report 2007-2008. ACT: Blue Star Print Group; 2008.

24. Australian public health data (2007-2008). Persons employed in health and community services. Australian Institute of Health and Welfare, 2008.

http://www.aihw.gov.au/publications/hwl/hwl4310677/table 1 8 occupation by weekly income.xls - 2009-03-24 (Accessed 07/2009)

25. Medicare Benefits Schedule July 2009. ACT: Commonwealth Government of Australia; 2009.

26. Wolowacz SE, Roskell NS, Maciver F, Beard SM, Robinson PA, Plumb JM, Dolan G, Brenkel IJ. Economic evaluation of dabigatran etexilate for the prevention of venous thromboembolism after total knee and hip replacement surgery. Clin Ther. 2009;31(1):194-212.

27. Australian hospital statistics (2007-2008). Australian Institute of Health and Welfare, 2008.

28. Wallentin L, Ezekowitz M, Simmers TA, et al; PETRO-investigators. Safety and efficacy of a new oral direct thrombin inhibitor dabigatran in atrial fibrillation: a dose finding trial with comparison to warfarin. Eur Heart J. 2005;26(suppl):482.

29. Wolowacz SE, Roskell NS, Plumb JM, Caprini JA, Eriksson BI. Efficacy and safety of dabigatran etexilate for the prevention of venous thromboembolism following total hip or knee arthroplasty. A meta-analysis. Thromb Haemost. 2009;101(1):77-85.

30. Ageno W. Rivaroxaban for the prevention of venous thromboembolism following major orthopedic surgery: the RECORD trials. Expert Rev Cardiovasc Ther. 2009;7(6):569-576.

31. Turpie AG, Lassen MR, Davidson BL, Bauer KA, Gent M, Kwong LM, Cushner FD, Lotke PA, Berkowitz SD, Bandel TJ, Benson A, Misselwitz F, Fisher WD; RECORD4 Investigators. Rivaroxaban versus enoxaparin for thromboprophylaxis after total knee arthroplasty (RECORD4): a randomised trial. Lancet. 2009;373(9676):1673-1680.

32. Broderick JP. Stroke therapy in the year 2025: burden, breakthroughs, and barriers to progress. Stroke. 2004;35(1):205-211.

33. Petersen P. Ximelagatran versus warfarin for stroke prevention in patients of nonvalvular atrial fibrillation. J. Amer. Coll. Cardiol. 2003;41:1445-1451.

34. Wells PS. Interactions of warfarin with drugs and food. Annals Intern Med. 1994;121:676-683.

35. Hylek EM. Acetaminophen and other risk factors for excessive warfarin anticoagulation. JAMA. 198;279:657-662.

36. Carabballo PJ. Long-term use of oral anticoagulation and the risk of fracture. Arch Intern Med. 1999;159:1750-1756.

37. Waldo AL. Stroke prevention in atrial fibrillation. JAMA. 2003;290:1093-1095.

38. Derry S, Loke YK. Risk of gastrointestinal haemorrhage with long term use of aspirin. BMJ. 2000;321:1170-1171.

39. Diener H-C, Connolly SJ, Ezekowitz MD, Wallentin L, Reilly PA, Yang S, Xavier D, Pasquale GD, Yusuf S. Dabigatran compared with warfarin in patients with atrial fibrillation and previous transient ischeamic attack or stroke: a subgroup analysis of RE-LY trial. Lancet Neurol. 2010;9:1157-1163.

40. Connolly SJ, Ezekowitz MD, Yusuf S, Eikelboom J, Oldgren J, Parekh A, Pogue J, Reilly PA, Themeles E, Varrone J, Wang S, Alings M, Xavier D, Zhu J, Diaz R, Lewis BS, Darius H, Diener, H-C, Joyner CD, Wallentin L. Dabigatran versus Warfarin in Patients with Atrial Fibrillation. N Eng J Med. 2009;361:1139-1151.

41. Buller HR, Lensing AW, Prins MH, Agnelli G, Cohen A, Gallus AS, Misselwitz F, Raskob G, Schellong S, Segers A. A dose-ranging study evaluating once-daily oral administration of the factor Xa inhibitor rivaroxaban in the treatment of patients with acute symptomatic deep vein thrombosis: the Einstein-DVT Dose-Ranging Study. Blood. 2008;112:22422247

42. Patel MR. Rivaroxaban - Once daily, oral, direct factor Xa inhibition compared with vitamin K antagonism for prevention of stroke and embolism trial in atrial fibrillation: Rationale and design of the ROCKET AF study. Am Heart J. 2010;159:340-347

43. National Institute of Health and Clinical Excellence. Final appraisal determination. Dabigatran etexilate for the prevention of venous thromboembolism after hip or knee replacement surgery in adults. http://www.nice.org.uk/nicemedia/pdf/DabigatranFAD.pdf. (Accessed 07/2009)

44. Mega JL, Braunwald E, Mohanavelu S, Burton P, Poulter R, Misselwitz F, Hricak V, Barnathan ES, Bordes P, Witkowski A, Markov V, Oppenheimer L, Gibson CM. Rivaroxaban versus placebo in patients with acute coronary syndromes (ATLAS ACS-TIMI 46): a randomised, double-blind, phase II trial. Lancet. 2009;374(9683):29-38.

45. Bauersachs RM. New Anticoagulants. Hamostaseologie. 2008;28(1-2):21-26.

46. Freeman JV, Zhu RP, Owens DK, Garber AM, Hutton DW, Go AS, Wang PJ, Turakhia MP. (2010). Cost-Effectiveness of Dabigatran Compared With Warfarin for Stroke Prevention in Atrial Fibrillation. Ann Intern Med. 2011;154(1):1-11.

47. McCullagh L, Tilson L, Walsh C, Barry M. A cost-effectiveness model comparing rivaroxaban and dabigatran etexilate with enoxaparin sodium as thromboprophylaxis after total hip and total knee replacement in the irish healthcare setting. Pharmacoeconomics. 2009;27(10):829-846. 